\title{
Cardiogenic shock in right ventricular infarction managed with a combined thermodilution and pacing pulmonary artery flotation catheter
}

\author{
J. D. EDWARDS, R. WILKINS \& H. GIBSON \\ Intensive Care Unit, University Hospital of South Manchester, Manchester, England
}

\section{SUMMARY}

When cardiogenic shock complicates right venticular infarction it is widely appreciated that rational therapy can only be achieved by use of plasma volume expansion and inotropic agents guided by invasive monitoring (Cohn et al., 1974). In these cases, there is a high incidence of symptomatic heart block and serious atrial and ventricular dysrhythmias (Cohn, 1979). Thus, venous access may be required for monitoring, pacing, infusion of fluid, and vasoactive or antiarrhythmic drugs. A case of right ventricular infarction complicated by cardiogenic shock, heart block, multiple arrhythmias and severe hypoxaemic respiratory failure is described. Technical problems in venous access were encountered and overcome by the use of a single multi-purpose catheter for haemodynamic monitoring, infusion of drugs and fluids and passage of a pacing wire. We believe that this is the first description of the use of such a catheter in the United Kingdom, although the use of a multi-purpose pulmonary artery flotation catheter with fixed pacing electrodes has been described before (Zaidan \& Freniere, 1983).

\section{CASE REPORT}

The patient was a 74-year-old female managed on the Coronary Care and Intensive Care Units of the University Hospital of South Manchester, England. She was admitted with typical cardiac chest pain of $2.5 \mathrm{~h}$ duration. The previous medical history was of one admission for left ventricular failure, and atrial fibrillation for which she received digoxin $0.125 \mathrm{mg}$ daily. On examination on admission, the apex rate was $95 /$ min, blood pressure was $100 / 60 \mathrm{mmHg}$, the jugular venous pressure was elevated to

Correspondence: Dr F. D. Edwards, Consultant Physician, Intensive Care Unit, University Hospital of South Manchester, Withington Hospital, Nell Lane, Manchester M20 8LR, England. 
$7 \mathrm{~cm}$ from the sternal angle and moved paradoxically with respiration. There was prominent right ventricular third heart sound but no clinical or radiological evidence of left ventricular failure. The 12-lead electrocardiograph showed the typical appearance $z$ of acute transmural inferior myocardial infarction and subsequently the peak level of creatinine phosphokinase was 2480 international units.

Six hours after admission she developed ventricular fibrillation which responded tof cardioversion. A lignocaine infusion was commenced at $4 \mathrm{mg} / \mathrm{min}$ after two boluso injections of $100 \mathrm{mg}$ and $50 \mathrm{mg}$ respectively. Two hours later, the rhythm changed to $\frac{\bar{\rho}}{\bar{\phi}}$ third degree heart block with a ventricular rate of $38 / \mathrm{min}$ and a systolic blood pressure of $70 \mathrm{mmHG}$. A temporary transvenous pacing electrode was inserted via the righes subclavian vein using an infraclavicular approach. A good position in the right ventricleos was obtained and the threshold was $0.3 \mathrm{~V}$. At a rate of $80 / \mathrm{min}$ the blood pressure was $80 / \mathrm{H}$ $60 \mathrm{mmHg}$. The patient was cold, comatose and anuric. Arterial $\mathrm{pO}_{2}$ on approximatelyo $60 \%$ oxygen was $11 \mathrm{kPa}$. A pulmonary artery flotation catheter was inserted via the righ! internal jugular vein using a high approach. The measured and calculated haemodynamic variables at this (point $\mathrm{A}$ ) and subsequent stages of her treatment are recorded in Table 1. These, taken with a paradoxical rise in right atrial pressure with respiration, a steep ' $y$ ' descent on the right atrial pressure tracing and an early diastolic dip in the righ 9 ventricular trace confirmed the diagnosis of right ventricular infarction (Lorell et al. $\overrightarrow{\text {, }}$ 1979). Plasma volume expansion with $600 \mathrm{ml}$ of modified fluid gelatin improved but did= not reverse the hypotension (point B). An infusion of dobutamine at $8 \mu \mathrm{g} / \mathrm{kg} / \mathrm{min}^{\mathrm{\Phi}}$ produced a satisfactory haemodynamic picture (point $\mathrm{C}$ ), with an increase in cardiac index from 1.5 to $2.4 \mathrm{l} / \mathrm{min}$.

Twenty-four hours later, a typical right venticular tachycardia developed. This not respond to $200 \mathrm{mg}$ of lignocaine or to four attempts at cardioversion. An image intensifier revealed that the pacing catheter was free in the cavity of the right ventricleg. It was removed and immediately the rhythm changed to third degree heart block alternating with ventricular standstill and paroxysmal ventricular fibrillation. The trachea was intubated and manual mechanical ventilation with $100 \%$ oxygen com-3 menced. Attempts were made to reinsert a pacing electrode. The right subclavian and internal jugular veins were cannulated several times, from a variety of routes by a highly experienced operator (J.D.E.), but a guide wire could not be advanced to the superior

Table 1 Haemodynamic progress of patient*

\begin{tabular}{lrllllllrr}
\hline Point & HR & MAP & RAP & PAOP & CI & SVRI & SVI & LVSWI \\
\hline A & 80 & 68 & 18 & 4 & $1 \cdot 1$ & 3636 & 14 & 12 & 14 \\
B & 80 & 72 & 20 & 16 & $1 \cdot 5$ & 2773 & 19 & 14 \\
C & 80 & 80 & 20 & 18 & $2 \cdot 4$ & 2066 & 30 & 24 & 8 \\
D & 100 & 63 & 20 & 22 & $1 \cdot 4$ & 2457 & 14 & 8 & 19 \\
E & 100 & 75 & 20 & 16 & 2.6 & 1815 & 26 & 19 \\
\hline
\end{tabular}

*HR: heart rate/min; MAP: mean arterial blood pressure (mmHg); RAP: right atrial pressure (mmHg); PAOP: pulmonary artery occlusion pressure $(\mathrm{mmHg})$; $\mathrm{CI}$ : cardiac index $\left(1 / \mathrm{m}^{2}\right)$; SVRI: systemic vascular resistance index (dyns $\left.\mathrm{cm}^{-5}\right)$; SVI: stroke volume index $\left(\mathrm{ml} / \mathrm{m}^{2}\right)$; LVSWI: left ventricular stroke work index $\left(\mathrm{g}-\mathrm{m} / \mathrm{m}^{2}\right)$. 
vena cava and a large haematoma developed. The rhythm changed to a sustained right ventricular tachycardia.

Amiodarone $300 \mathrm{mg}$ was infused and the rhythm changed to third degree heart block alternating with ventricular standstill. The pulmonary artery flotation catheter was removed from its introducer sheath in the right internal jugular vein and a pacing electrode was introduced. Capture was achieved with a poor position in the right ventricle and an unstable threshold of $3 \mathrm{~V}$. At a heart rate of $100 / \mathrm{min}$, the blood pressure was $75 / 60 \mathrm{mmHg}$.

A Swan Ganz Thermodilution Paceport Catheter (Model 9 A-931H-7.5F, Edwards Laboratories) was introduced via the left subclavian vein. By means of the displayed transduced waveform the correct position of the Paceport lumen in the right ventricle was confirmed and the Chandler transluminal ventricular pacing probe (model 98$100 \mathrm{H}$, Edwards Laboratories) was inserted. Immediate capture of the right ventricle was achieved with a threshold of $0.6 \mathrm{~V}$. At a rate of $100 / \mathrm{min}$, the blood pressure was $80 /$ $55 \mathrm{mmHg}$ (point D). After restablization with dobutamine $22 \mu \mathrm{g} / \mathrm{kg} / \mathrm{min}$ the haemodynamics improved (point E). After $72 \mathrm{~h}$ controlled mechanical ventilation on the Intensive Care Unit the patient made a good recovery, and was subsequently discharged from hospital with no neurological deficit and no symptoms of cardiac failure.

The Paceport catheter provides the ability to measure pulmonary artery, pulmonary artery occlusion, right ventricular and right artrial pressures, as well as cardiac output by the thermodilution method.

A lumen that terminates $19 \mathrm{~cm}$ from the top is provided for insertion of a Chandler transluminal pacing probe into the right ventricle whilst the catheter tip is in the pulmonary artery, allowing endocardial pacing. The Chandler probe is a 2.4 French gauge, bipolar, coaxial wire construction of a stainless steel round wire and a tefloncoated coiled flat wire. The Paceport catheter, and the distal $20 \mathrm{~cm}$ of the Chandler probe are heparin coated. The Paceport catheter represents development of the earlier 'Pacing TD Catheter' described by Zaidan \& Freniere (1983), for, whilst the earlier catheter had pacing electrodes embedded in the surface of the catheter and capture was, therefore, dependent upon wall contact by a catheter loop, the Paceport system allows the pacing probe tip to be in direct endocardial contact, as with the standard transvenous pacing method. Insertion of the system through a Percutaneous Catheter Insertion Kit (American Pharmasel, No. PA3800) allows manipulation of the catheter within a sterile sheath, and infusion of drugs into the chosen great vein via a side-arm attachment.

\section{DISCUSSION}

Many aspects of the management of shock associated with right ventricular infarction are highlighted by this case: shock without a critically elevated pulmonary artery occlusion pressure (Cohn et al., 1974), partial response to controlled plasma volume expansion (Cohn, 1979), life threatening ventricular dysrhythmias unresponsive to anti-arrhythmic drugs, heart block with poor haemodynamic response to pacing (Lorell 
et al., 1979) and hypoxaemia requiring high concentrations of oxygen and mechanica ventilation (Edwards et al., 1986).

At a critical moment during the resuscitation of this patient, the multi-purpos pulmonary artery pacing catheter was crucial to the successful outcome. The unique. properties of such catheters justify their relative expense in the clinical situation with $\overrightarrow{\vec{s}}$ which we were faced and further studies to evaluate the role of these catheters in complicated cases of right ventricular infarction are needed.

\section{REFERENCES}

Cohn J. N., Guiha N. H., Broder M. I. \& Lima C. J. (1974) Right ventricular infarction: clinical anळ haemodynamic features. American fournal of Cardiology 33, 209-14.

Cohn J. N. (1979) Right ventricular infarction revisited. American fournal of Cardiology 43, 666-8.

Edwards D., Whittaker S. \& Prior A. (1986) Cardiogenic shock without a critically raised left ventricular end diastolic pressure: management and outcome in eighteen patients. British Heart fournal 55, 549-53.

Lorell B., Leinbach R. C., Pohost G. M., Gold H. K., Dinsmore R. E., Hutter A. M., Pastore J. O. \&N Desanctis R. W. (1979) Right ventricular infarction. Clinical diagnosis and differentiation from cardiag tamponade and pericardial constriction. American fournal of Cardiology 43, 465-71.

Zaidan J. R. \& Freniere S. (1983) Use of a pacing pulmonary artery catheter during cardiac surgery. Annals of Thoracic Surgery 35, 633-6.

Received 12 December 1986; accepted 7 fanuary 1987 